\title{
Sex ratio shift caused by hyperparasitism in the solitary parasitoid Lysiphlebus hirticornis (Hymenoptera: Braconidae: Aphidiinae)
}

\author{
MANFRED MACKAUER ${ }^{1}$ and WolfGANG VÖLKL ${ }^{2}$ \\ ${ }^{1}$ Department of Biological Sciences, Simon Fraser University, 8888 University Drive, Burnaby, B.C., V5A 1S6, Canada; \\ e-mail: mackauer@sfu.ca \\ ${ }^{2}$ Lehrstuhl für Tierökologie I, Universität Bayreuth, D-95440 Bayreuth, Germany; e-mail: wolfgang.voelk1@uni-bayreuth.de
}

Key words. Aphidiinae, Braconidae, Lysiphlebus hirticornis, aphid parasitoid, offspring mortality, hyperparasitism, Syrphophagus aphidivorus, sex ratio

\begin{abstract}
We examined the influence of offspring mortality caused by hyperparasitism on the secondary sex ratio of Lysiphlebus hirticornis Mackauer, a solitary endoparasitoid of the aphid Metopeurum fuscoviride Stroyan, in the field. Females of $L$. hirticornis produce pseudo-gregarious broods, which may comprise more than 200 offspring. Hyperparasitoids [mainly Syrphophagus aphidivorus (Mayr)] attacked and killed up to $60 \%$ of the primary parasitoids inside mummified aphids, especially late in the season. Hyperparasitized broods were larger than hyperparasitoid-free broods, which suggests that the risk of hyperparasitism increased with mummy density. We tested the hypothesis that mortality caused by hyperparasitism is greater for female than male offspring of $L$. hirticornis. If mummy quality scales with mummy size, hyperparasitoids should choose the relatively larger over the relatively smaller mummies. In the absence of hyperparasitism, broods of L. hirticornis included approximately two daughters for each son; the sex ratio did not vary with brood size. In hyperparasitized broods, the sex ratio was nearly even. This result indicates that relatively more female offspring (developing in the larger mummies) than male offspring (developing in the smaller mummies) were killed by hyperparasitoids. We propose that sex-differential offspring mortality in L. hirticornis is the result of differences in optimal host choice between the primary parasitoid and the hyperparasitoids.
\end{abstract}

\section{INTRODUCTION}

Sex determination by haplodiploidy enables parasitoid females to determine offspring sex by controlling sperm release, with sons and daughters developing from unfertilized and fertilized eggs, respectively (Cook \& Crozier, 1995). Because daughters, rather than sons, may gain relatively more in fitness from an increase in size, mothers are expected to deposit fertilized eggs selectively in high-quality, large hosts containing more resources (King, 1993; Godfray, 1994). The sex ratio at maturity, however, can differ from the primary sex ratio at oviposition if the risk of mortality is greater for one sex than the other (Hardy \& Cook, 1995; Hardy et al., 1998). Mortality among parasitoid offspring can be caused by, for example, host immunity (Salt \& van den Bosch, 1967; Hufbauer \& Via, 1999; Oliver et al., 2003), low host quality (Otto \& Mackauer, 1998; Harvey et al., 2004), competition between parasitoid larvae (Wylie, 1965; van Baaren et al., 1999), predation (Colfer \& Rosenheim, 2001; Snyder \& Ives, 2003), and hyperparasitism (Sullivan \& Völkl, 1999; Brodeur, 2000). Because females often have more stringent nutritional requirements than males (Stadler \& Mackauer, 1996; Harvey et al., 1998), the immature stages of females may be at greater risk of mortality in low-quality hosts (Waage, 1986). Changes in the brood sex-ratio due to competition for limiting host resources are well documented in gregarious parasitoids (Wylie, 1965; Sandlan, 1979; Suzuki et al., 1984; Takagi, 1986), which produce many offspring per host. However, in solitary parasitoids, which produce only one offspring per host, evidence suggesting that a male-biased sex ratio is the result of sex-differential offspring mortality in lowquality hosts (Wellings et al., 1986) was challenged (Cloutier et al., 1991; Pandey \& Singh, 1999).

In contrast to immature mortality due to variations in host quality, hyperparasitism can be readily assessed. Many species of Hymenoptera develop as secondary or even tertiary parasitoids on the immature stages of other (primary) parasitoids, which are attacked either before or after the host has been killed by the primary parasitoid. Hyperparasitoids often destroy $80 \%$ to $90 \%$ of the primary parasitoids in some associations (Luck et al., 1981; Höller et al., 1993; Brodeur \& Rosenheim, 2000). Although most studies implicitly assume that host choice by hyperparasitoids is random with regard to the sex of the primary parasitoid (Höller et al., 1993; Meyhöfer \& Klug, 2002; Snyder \& Ives, 2003), this assumption may not be valid in general. Sequeira \& Mackauer (1993) examined the mean sex ratio and mortality in field populations of Aphidius ervi Haliday (Hymenoptera: Braconidae: Aphidiinae), a solitary parasitoid of the pea aphid, Acyrthosiphon pisum (Harris) (Hemiptera: Aphidoidea: Aphididae). They found that mortality from all sources including hyperparasitism was greater among parasitoids eclosing from the relatively larger mummies, which contained a higher proportion of females. Similarly, Heinz (1996) showed that female progeny of Chrysocharis nephereus (Walker) (Hymenoptera: Eulophidae), an ectoparasitoid of leafminer larvae, were hyperparasitized more frequently than male progeny; male and female progeny were produced disproportionately on small and 
large hosts, respectively. Mackauer \& Lardner (1995) reported that Dendrocerus carpenteri Curtis (Hymenoptera: Megaspilidae), an ectohyperparasitoid developing on the prepupal and pupal stages of aphidiine wasps inside mummified aphids, accepted small and large pea-aphid mummies containing $A$. ervi in proportion to their availability, both in laboratory experiments and in the field. Hyperparasitoid females, however, allocated offspring sexes according to host size, depositing fertilized eggs selectively in the relatively larger mummies (Chow \& Mackauer, 1996; Otto \& Mackauer, 1998).

We examined the influence of hyperparasitism on brood size and sex ratio in natural populations of Lysiphlebus hirticornis Mackauer (Hymenoptera: Braconidae: Aphidiinae), a solitary endoparasitoid of the aphid Metopeurum fuscoviride Stroyan (Hemiptera: Aphidoidea: Aphididae). Females in the genus Lysiphlebus including L. hirticornis and L. cardui (Marshall) produce broods comprising 200-300 progeny, especially in aphid colonies attended by trophobiotic ants (Völkl, 1997; Mackauer \& Völkl, 2002); such broods were termed quasi-gregarious by van den Assem et al. (1980). Mackauer \& Völkl (2002) reported that hyperparasitoidfree broods of $L$. hirticornis included approximately two daughters for each son; this ratio did not vary with brood size. The variance of the number of males in broods differing in size was consistent with overdispersion, which is expected if mothers adjust the primary sex ratio for developmental mortality (Nagelkerke \& Hardy, 1994; Hardy et al., 1998). We tested the hypothesis that offspring mortality as a result of hyperparasitism is random with regard to the sex of the primary parasitoid. If hyperparasitoids accept equally all mummy sizes and both offspring sexes of $L$. hirticornis, the sex ratio at eclosion should be the same in hyperparasitized and hyperparasitoid-free broods; but hyperparasitized broods should be smaller on average. Alternatively, if hyperparasitoids select the relatively larger mummies (which contain a greater proportion of female progeny) among those available, the risk of mortality should be greater for female than male progeny and hence the average sex ratio of the primary parasitoid should shift from a female-bias towards an even ratio or even a male-bias in hyperparasitized broods.

\section{MATERIAL AND METHODS}

\section{Experimental system}

We used a tritrophic system consisting of the aphid M. fuscoviride, its primary parasitoid L. hirticornis, and several species of hyperparasitoids. Because hyperparasitoids develop as parasitoids of other (primary) parasitoids, the latter may also be called the "primary" host and aphids the "secondary" host of the hyperparasitoid. However, to avoid confusion, we use the term "primary parasitoid" or simply parasitoid to refer to L. hirticornis, and the term host to refer to $M$. fuscoviride. In central Europe, L. hirticornis parasitizes exclusively $M$. fuscoviride feeding on tansy, Tanacetum vulgare L. (Compositae) (Mackauer \& Starý, 1967). Guarding ants ignore Lysiphlebus females, which mimic the aphids' epicuticular hydrocarbon pattern (Liepert \& Dettner, 1993; Dettner \& Liepert, 1994). This chemical mimicry allows parasitoids to forage undisturbed in ant-attended colonies (Mackauer \& Völkl, 1993; Völkl, 1994, 1997) and to mate on the natal patch (W. Völkl, unpubl.). The presence of ants, however, does not generally provide protection against hyperparasitoids foraging for mummies (Kaneko, 2003) as some species of hyperparasitoids have evolved strategies to overcome ant aggression by either chemical defence (Völkl et al., 1994) or behavioural adaptations (Hübner \& Völkl, 1996).

Most of the hyperparasitoids reared from L. hirticornis belonged to Syrphophagus (= Aphidencyrtus) aphidivorus (Mayr) (Hymenoptera: Encyrtidae), a generalist hyperparasitoid of aphidiine wasps. Its oviposition behaviour and larval development were examined by Kanuck \& Sullivan (1992), who reported that females deposit an egg directly in the primary parasitoid. The hyperparasitoid larva develops initially as an endoparasitoid but completes development as an ectoparasitoid feeding on host remains. Females may oviposit both in live aphids (ie., prior to mummification) and in mummified aphids, which latter are strongly preferred (Buitenhuis et al., 2004a).

Mummy samples were collected throughout the summer, beginning with the offspring of the overwintering parasitoid generation, in the vicinity of Bayreuth, Germany, during the period 1994-1998. The fundatrix generation of M. fuscoviride appeared relatively late in the season, from early to the middle of June. Aphid populations grew rapidly in number, and winged aphids dispersed to different plants to establish new colonies. Rates of parasitism increased during the season and approached $100 \%$ during mid-summer, especially in ant-attended colonies (Mackauer \& Völkl, 1993; Weisser, 2000). Early in the season when few parasitoids were present, all mummified aphids found in a colony can be reasonably assumed to contain one brood, i.e., they were the progeny of a single parasitoid female produced during one foraging bout. Colonies of M. fuscoviride, however, may persist over several weeks or even months on suitable host plants and spread over different plant structures. For this reason, only aphids forming a discrete colony on the host plant were sampled. As the number of unparasitized aphids declined, the probability increased that a single aphid colony was visited by several parasitoid females foraging together or in succession. Because broods produced by different females are difficult to distinguish, we took the additional precaution of excluding from the analysis any samples from which the primary parasitoids eclosed over a period exceeding $1 \mathrm{~d}$; eclosion over a longer period suggests, but does not prove, that the aphids may have been parasitized during successive oviposition bouts by the same or different females. Mummy samples were placed separately in glass vials stoppered with cotton or, in the case of very large samples, in screened plastic cages. After all parasitoids and hyperparasitoids had eclosed from the mummies, the insects were identified and counted by species and sex. Samples were divided into hyperparasitoid-free broods and broods containing hyperparasitoids.

The timing of parasitoid emergence from diapause depends on average daily temperatures (Campbell et al., 1974), which varied between years. We used, therefore, a physiological timescale (in day-degrees, $\mathrm{DD}^{\circ} \mathrm{C}$ ) to test for seasonal variations in brood size and sex ratio; average daily temperatures for Bayreuth were obtained from the Deutsche Wetterdienst. We used a temperature threshold for development of $6^{\circ} \mathrm{C}$, which is marginally lower than the estimated threshold of $6.5^{\circ} \mathrm{C}$ of Diaeretiella rapae (M'Intosh), a parasitoid of the cabbage aphid, in the Netherlands (Campbell et al., 1974). Because we could not exclude seasonal effects (Mishra \& Singh, 1991; Sequeira \& Mackauer, 1993), we compared differences in brood size and sex ratio between hyperparasitized and hyperparasitoid-free broods collected on the same day and in the same location. For the analysis, we assumed further that all females of L. hirti- 
TABLE 1. Influence of hyperparasitism on brood size in Lysiphlebus hirticornis parasitizing Metopeurum fuscoviride on tansy near Bayreuth, Germany, during 1994-98. Sample size is the number of successfully parasitized aphids (i.e., mummies), and brood is the number of parasitoid offspring eclosing from the mummies. In the absence of hyperparasitism, one offspring per parasitized aphid is assumed to complete development (i.e., sample and brood size are the same). The sex ratio is the proportion of males among offspring pooled between broods. Calendar days were converted to day-degrees $\left(\mathrm{DD}^{\circ} \mathrm{C}\right)$ above $6^{\circ} \mathrm{C}$ for days after and including April 1.

\begin{tabular}{lrccccccc}
\hline & \multicolumn{3}{c}{ Broods without hyperparasitoids } & \multicolumn{3}{c}{ Broods attacked by hyperparasitoids } \\
\cline { 2 - 8 } $\mathrm{DD}^{\circ} \mathrm{C}$ & $\mathrm{n}$ & $\begin{array}{c}\text { Sample size } \\
(\mathrm{m} e a n \pm \mathrm{SE})\end{array}$ & Sex ratio & $\mathrm{n}$ & $\begin{array}{c}\text { Sample size } \\
(\text { mean } \pm \mathrm{SE})\end{array}$ & $\begin{array}{c}\text { Brood size } \\
\text { (mean } \pm \text { SE) }\end{array}$ & Sex ratio & $\begin{array}{c}\% \text { hyper- } \\
\text { parasitism }\end{array}$ \\
\hline 732.3 & 13 & $34.5 \pm 17.8$ & 0.393 & 3 & $56.7 \pm 14.0 \mathrm{~ns}$ & $55.7 \pm 14.0 \mathrm{~ns}$ & $0.365 \mathrm{~ns}$ & 1.8 \\
843.7 & 27 & $74.4 \pm 13.0$ & 0.367 & 6 & $104.8 \pm 23.6 \mathrm{~ns}$ & $59.0 \pm 11.4 \mathrm{~ns}$ & $0.435^{*}$ & 43.7 \\
884.6 & 5 & $29.2 \pm 13.5$ & 0.466 & 6 & $91.3 \pm 23.3 \mathrm{~ns}$ & $63.2 \pm 19.4 \mathrm{~ns}$ & $0.451 \mathrm{~ns}$ & 30.8 \\
898 & 28 & $15.3 \pm 2.6$ & 0.303 & 10 & $111.7 \pm 31.5^{* * *}$ & $72.4 \pm 21.8^{* *}$ & $0.497^{* * *}$ & 35.2 \\
981.4 & 11 & $28.5 \pm 6.2$ & 0.431 & 21 & $74.7 \pm 8.8^{* * *}$ & $32.9 \pm 6.0 \mathrm{~ns}$ & $0.503^{*}$ & 56.0 \\
1010 & 1 & 3 & & 17 & $77.5 \pm 12.0 \mathrm{~ns}$ & $29.0 \pm 4.9 \mathrm{~ns}$ & 0.492 & 62.6 \\
1124.3 & 2 & $28.0 \pm 4.0$ & 0.232 & 15 & $67.3 \pm 11.3 \mathrm{~ns}$ & $25.7 \pm 5.7 \mathrm{~ns}$ & $0.330 \mathrm{~ns}$ & 61.8 \\
Total & 87 & $39.1 \pm 5.6$ & & 78 & $81.5 \pm 6.3$ & $40.9 \pm 4.3$ & & \\
\hline
\end{tabular}

Differences between means within rows were tested for statistical significance by the Mann-Whitney $U$-test (for sample and brood sizes; see Materials and Methods for terminology) and by the $G$-test for cross-classified data (for sex ratio) (ns, $\mathrm{P} \geq 0.05 ; *, \mathrm{P}<$ $0.05 ; * *, \mathrm{P}<0.01 ; * *, \mathrm{P}<0.001)$.

cornis were mated and could produce both sons and daughters. Several studies have shown that unmated females (which can produce only male offspring from unfertilized eggs) are extremely rare in field populations of aphidiine wasps (Mackauer, 1976; Mackauer \& Völkl, 2002).

\section{Terminology}

We distinguish between the terms sample and brood. Sample refers to the number of successfully parasitized aphids, which is measured by the number of mummies found in a colony. Brood refers to the number of progeny surviving in a sample. For hyperparasitoid-free broods only, brood size is the same as sample size. This definition ignores any mortality that may occur during immature development prior to aphid mummification. Pre-mummification mortality resulting from host immune responses was observed in several species of aphidiine wasps including Monoctonus crepidis (Marshall) developing in nonhost aphids (Griffiths, 1961) and Aphidius ervi Haliday developing in resistant strains of the pea aphid (Hufbauer \& Via, 1999; Hufbauer, 2002; Oliver et al., 2003; Ferrari et al., 2004). It is assumed that mortality risk from host resistance and larval competition in superparasitized aphids is the same for both parasitoid sexes. Because only one offspring per host completes development, brood size does not vary with superparasitism, which is the number of parasitoid eggs laid per host. The brood sex ratio is the secondary sex ratio at eclosion and is measured by the proportion of sons among offspring.

\section{Data analysis}

We used regression through the origin to examine the functional relationship between the number of males and brood size; the regression slope yields the overall sex ratio. For each sampling date, the mean sex ratio was estimated by pooling the numbers of males and females between samples, separately for hyperparasitized and hyperparasitoid-free broods; differences were tested by the $G$-test of independence adjusted for continuity by Williams's correction (Sokal \& Rohlf, 1995, p. 703). Because sample and brood sizes were not normally distributed, we used the nonparametric Mann-Whitney $U$-test to test the statistical significance of differences between the ranked data (Sokal \& Rohlf, 1995, p. 427) and isotonic regression to test seasonal changes in the percentages of hyperparasitized broods and hyperparasitized mummies within broods, using 10000 iterations (Sokal \& Rohlf, 1995, p. 811). Probabilities of inde- pendent tests of significance were combined by Fisher's test (Sokal \& Rohlf, 1995, p. 794).

\section{RESULTS}

We collected mummified aphids in 165 natural colonies, comprising a total of 9761 mummies; 78 samples (3166 mummies; 32.4\%) contained hyperparasitoids. The mean number of mummies per sample (mean $\pm \mathrm{SE}=$ $59.2 \pm 4.5$; maximum $=297$ ) did not differ between collection dates (1-way ANOVA, $F_{6,158}=1.954, P=0.08$ ). Syrphophagus aphidivorus $(92.2 \%)$ was by far the most common species of hyperparasitoid, with the remaining specimens representing mainly unidentified species of Alloxystinae (Cynipidae) and Dendrocerus (Megaspilidae).

Hyperparasitism increased with the season in terms of the percentage of broods attacked, with over $90 \%$ of all samples containing hyperparasitoids in late summer (isotonic regression, $E^{2}=0.938$, one-tailed $P=0.012$ ) (Table 1). As the percentage of attacked broods increased so did the percentage of L. hirticornis killed by hyperparasitoids, from approximately $2 \%$ in early July $\left(732 \mathrm{DD}^{\circ} \mathrm{C}\right)$ to $60 \%$ in late July and early August $\left(>1000 \mathrm{DD}^{\circ} \mathrm{C}\right.$ ) (isotonic regression, $E^{2}=0.969$, one-tailed $P=0.005$ ). The number of hyperparasitized mummies was correlated with the total number of mummies per sample (product-moment correlation coefficient, $r=0.759, P<0.001, n=75)$. Hyperparasitized samples $(81.5 \pm 6.3$; maximum $=297)$ were significantly larger on average than samples without hyperparasitoids $(39.1 \pm 5.6$; maximum $=233$; Fisher's combined probability of independent Mann-Whitney $U$-tests, $X^{2}{ }_{14}=47.93, P<0.001$ ) (Table 1). However, the mean number of surviving $L$. hirticornis per sample did not differ between hyperparasitized and hyperparasitoidfree broods (Fisher's test, $X^{2}{ }_{14}=22.37, P=0.07$ ), with one exception. In one collection $\left(898 \mathrm{DD}^{\circ} \mathrm{C}\right)$, samples attacked by hyperparasitoids were 7-times larger on average than samples not so attacked (Mann-Whitney $U$-test, $U=39, P<0.001)$, which accounted for hyper- 
parasitized broods being larger than hyperparasitoid-free broods $(U=60, P=0.007)$.

Within collection dates, the proportion of males among offspring was greater in broods attacked by hyperparasitoids than in those that had escaped hyperparasitism (Fisher's test for combining probabilities of independent $G$-tests, $X^{2}{ }_{14}>48.40, P<0.001$ ) (Table 1). Regression through the origin of the number of males on brood size showed that the observed change in the sex ratio was independent of the number of offspring per brood. Hyperparasitoid-free broods contained approximately two daughters for each son (regression slope, $b=0.366 ; 95 \%$ CI of $\left.b, 0.351-0.381 ; F_{1,86}=2235, P<0.001\right)$, whereas broods subject to hyperparasitism had a nearly even ratio of $1: 1$ sons to daughters $(b=0.457 ; 95 \%$ CI of $b$, $\left.0.432-0.481 ; F_{1,77}=1368, P<0.001\right)$.

Brood size in $S$. aphidivorus was $37.42 \pm 3.66$ (mean \pm SE; $n=78$ ), with a maximum of 138 individuals. The sex ratio did not differ from a $1: 1$ ratio $(b=0.493 ; 95 \% \mathrm{CI}$ of $\left.b, 0.470-0.516 ; F_{1,75}=1869, P<0.001\right)$. Because mummy samples were selected to represent single-female broods of $L$. hirticornis rather than of S. aphidivorus, it is possible that the hyperparasitoids eclosing from individual mummy samples were the progeny of several attacks by one or more females.

\section{DISCUSSION}

The secondary sex ratio at maturity will differ from the primary sex ratio if developmental mortality is greater in one sex than the other. Although hyperparasitism is probably the most frequent cause of offspring mortality in aphidiine wasps, most studies implicitly assume that both sexes of the primary parasitoid are equally at risk (Höller et al., 1993; Snyder \& Ives, 2003). We compared brood size and sex ratio between hyperparasitized and hyperparasitoid-free single-female broods of $L$. hirticornis collected at the same location over several seasons near Bayreuth, Germany. Over $90 \%$ of the hyperparasitoids reared from $L$. hirticornis belonged to $S$. aphidivorus, which typically attacks aphidiine larvae inside mummified aphids although females may also oviposit in live aphids (Kanuck \& Sullivan, 1992; Buitenhuis et al., 2004a). Both the percentage of hyperparasitized samples and the percentage of hyperparasitized mummies per sample increased with the season. Samples containing hyperparasitoids were larger than samples without hyperparasitoids (Table 1). Aphid parasitoids and hyperparasitoids are both attracted to aphid honeydew, which acts as a contact kairomone (Budenberg, 1990; Cloutier \& Bauduin, 1990; Han \& Chen, 2002; Buitenhuis et al., 2004b). Because the amount of honeydew produced increases with the number of aphids in a colony, large colonies are more likely to be found by parasitoids. Interestingly, the average number of parasitoids eclosing from the mummy samples did not differ between hyperparasitized broods and broods that had escaped hyperparasitism (Table 1). We have no biological explanation to account for this result.
Hyperparasitoid-free broods of $L$. hirticornis contained approximately two daughters for each son, which was independent of brood size (Table 1). The mean sex ratio after hyperparasitism, in contrast, approached a $1: 1$ ratio of sons to daughters, which is expected if more female than male progeny die. Because our field study was observational, rather than manipulative, other factors may have contributed to the observed sex-ratio shift. For example, mummy samples from large aphid colonies could have comprised the offspring of several parasitoid females, rather than one only. While we cannot completely exclude the possibility of sampling bias due to multiple foundresses, we found no evidence of a change in the sex ratio over a broad range of brood sizes in the absence of hyperparasitism (Table 1) (Mackauer \& Völkl, 2002). Selective predation on large mummies could also result in a sex-ratio shift, analogous to the effect of hyperparasitism.

We propose that sex-differential offspring mortality in L. hirticornis is the result of differences in host choice between the primary parasitoid and mummy hyperparasitoids. Most aphids have a well-developed defence and escape repertoire (Klingauf, 1966; Losey \& Denno, 1998). Because older instars and adults are more likely to escape or are more risky to attack (Chau \& Mackauer, 2001), many aphidiine wasps choose early instars over late instars and adult aphids for oviposition (Mackauer et al., 1996; Völkl \& Mackauer, 2000), which is reflected in the distribution of mummy sizes in the field. For example, Mackauer \& Lardner (1995) found that 72.9\% $(n=2990)$ of pea aphids parasitized by $A$. ervi had died in the fourth instar (i.e., they were parasitized in the first and early second instar; Sequeira \& Mackauer, 1992), while only $27.1 \%$ had been parasitized at a later age and died as adults. Because body size is generally more important for a daughter's than a son's fitness (van den Assem et al., 1989; Visser, 1994; Cloutier et al., 2000), host-quality models predict that mothers should deposit more fertilized eggs in the relatively larger hosts and more unfertilized eggs in the relatively smaller hosts (King, 1993; Godfray, 1994). This prediction is well supported by empirical evidence showing that the sex ratio in aphidiine wasps becomes more female-biased with an increase in host size (Cloutier et al., 1991; Singh \& Pandey, 1997; Pandey \& Singh, 1999). It is also consistent with anecdotal observations on L. hirticornis. In a sample of 101 mummies collected at the same time and location, offspring eclosing from the relatively larger "adult" mummies (mean size, $1.91 \mathrm{~mm} ; n=78$ ) had a female-biased sex ratio of 0.27 , whereas those eclosing from the relatively smaller "fourth-instar" mummies (mean size, 1.68 $\mathrm{mm} ; n=23$ ) had a nearly-even sex ratio of 0.48 (W. Völkl, unpubl.).

Mummified aphids, however, are unable to escape or defend themselves against hyperparasitoid attack. Host choice by mummy hyperparasitoids, therefore, should not be constrained by any host defences although handling time can vary with mummy type and female experience (Chow \& Mackauer, 1999). If mummy quality scales with 
mummy size (Chow \& Mackauer, 1996, 1999), a preference for large over small mummies by the hyperparasitoid will result in a proportionately greater mortality risk for female than male progeny of the primary parasitoid and, in turn, reduce any female-bias in its primary sex ratio. In contrast, a preference for small over large mummies will reduce any male-bias in the primary sex ratio as long as large mummies contain a relatively greater proportion of female progeny. We suspect that the form of the relationship is association-specific, depending on the offspringand sex-allocation strategies of both the primary parasitoid and the hyperparasitoids. Although there is insufficient information available on host choice by $S$. aphidivorus, our results suggest a modest preference for the relatively larger mummies, similar to $D$. carpenteri (Chow \& Mackauer, 1996; Otto \& Mackauer, 1998).

Sex-ratio models incorporating developmental mortality assume that females of gregarious parasitoids can assess the risk of offspring mortality and adjust the primary sex ratio accordingly (Nagelkerke \& Hardy, 1994; Hardy \& Cook, 1995; Hardy et al., 1998). This assumption, however, may not apply in general but only to risks that the female can assess at oviposition by antennation and ovipositor probing, such as host quality and superparasitism. Moreover, gregarious and solitary parasitoids can respond differently to variations in host quality. Because gregarious parasitoids deposit a clutch of eggs in the same host individual, host choice should reflect a compromise in terms of quality for male and female development. In contrast, solitary species normally deposit only one egg per host. By controlling sperm release, a solitary female can deposit an unfertilized egg, as opposed to a fertilized egg, if the risk of developmental mortality is greater for a daughter than a son and vice versa. The mean sex ratio is the result of a sequence of separate decisions by the mother in choosing the "best" available host for each offspring, one at a time. Therefore, sex-differential mortality caused by oviposition in low-quality hosts is less likely and compensation for such mortality, perhaps, would not be under strong selection in solitary parasitoids.

A female, however, cannot assess the risk of hyperparasitism and predation, which occur after she has committed her progeny to a particular host. Although Höller et al. (1994) suggested that aphidiine wasps can detect and avoid areas where hyperparasitoids are present, it is not clear how avoidance behaviour could protect offspring in already parasitized aphids (Völkl et al., 1995). Also, most mummy hyperparasitoids are generalists (Sullivan \& Völkl, 1999), which can survive on many species of primary parasitoids; hyperparasitoid-free space may therefore not exist. In conclusion, we propose that the observed difference in the sex ratio between hyperparasitoid-free and hyperparasitized broods (Table 1) does not prove that females of $L$. hirticornis adjust the primary sex ratio to compensate for any sex-differential developmental mortality. Although our results would be consistent with such an hypothesis (Nagelkerke \& Hardy, 1994; Hardy et al., 1998), the balance of the evidence does not support this interpretation. First, hyperparasitism increased with the season, being virtually absent in early summer. Female bias in hyperparasitoid-free broods therefore should have also increased with the season, which is not the case (Mackauer \& Völkl, 2002). Second, a $1: 1$ sex ratio after hyperparasitism is expected in outbreeding species. Most females of L. hirticornis, however, mate on the natal patch before dispersal. In single-foundress broods the sex ratio was female-biased, indicating a mating structure of complete or partial sib mating and local mate competition (Mackauer \& Völkl, 2002). And third, the risk of developmental mortality as a result of hyperparasitism varies with the presence of trophobiotic ants, which is site-specific (Völkl, 1997). We have shown that, in L. hirticornis, offspring sex allocation according to host quality, with more daughters being allocated to the relatively larger hosts and more sons to the relatively smaller hosts, may expose daughters to increased risk of hyperparasitism if hyperparasitoids also prefer large hosts for their offspring. Such allocation patterns will result in a shift of the population sex ratio in the primary parasitoid.

ACKNOWLEDGEMENTS. We thank J. Rosenheim (University of California, Davis) for his helpful criticism of an earlier manuscript draft; and the Deutsche Wetterdienst (Nürnberg) for the meteorological data. The Natural Sciences and Engineering Research Council of Canada provided financial support to M.M.

\section{REFERENCES}

Assem J. van den, Gijswitt J.J. \& Nübel B.K. 1980: Observations on courtship and mating strategies in a few species of parasitic wasps (Chalcidoidea). Neth. J. Zool. 30: 208-227.

Assem J. van den, van Iersel J.J.A. \& Los-den Hartog R.L. 1989: Is being large more important for female than male parasitic wasps? Behaviour 108: 160-195.

BAAREN J. van, LANDRY B.L. \& BoIvin G. 1999: Sex allocation and larval competition in a superparasitizing solitary egg parasitoid: competing strategies for an optimal sex ratio. Funct. Ecol. 13: 66-71.

BRodeur J. 2000: Host specificity and trophic relationships of hyperparasitoids. In Hochberg M. \& Ives A.R. (eds): Parasite Population Biology. Princeton University Press, Princeton, NJ, pp. 139-162.

BRodeur J. \& Rosenheim J.A. 2000: Intraguild interactions in aphid parasitoids. Entomol. Exp. Appl. 97: 93-108.

BUDENBERG W.J. 1990: Honeydew as a contact kairomone for aphid parasitoids. Entomol. Exp. Appl. 55: 139-148.

Buitenhuis R., Boivin G., Vet L.E.M. \& Brodeur J. 2004a: Preference and performance of the hyperparasitoid Syrphophagus aphidivorus (Hymenoptera: Encyrtidae): fitness consequences of selecting hosts in live aphids or aphid mummies. Ecol. Entomol. 29: 648-656.

Buttenhuis R., McNeil J.N., Boivin G. \& Brodeur J. 2004b: The role of honeydew in host searching of aphid hyperparasitoids. J. Chem. Ecol. 30: 273-285.

Campbell A., Frazer B.D., Gilbert N., Gutierrez A.P. \& MACKAUER M. 1974: Temperature requirements of some aphids and their parasites. J. Appl. Ecol. 11: 431-438.

Chau A. \& Mackauer M. 2001: Host-instar selection in the aphid parasitoid Monoctonus paulensis (Hymenoptera: Braconidae, Aphidiinae): assessing costs and benefits. Can. Entomol. 133: 549-564. 
Chow A. \& Mackauer M. 1996: Sequential allocation of offspring sexes in the hyperparasitoid wasp, Dendrocerus carpenteri. Anim. Behav. 51: 859-870.

Chow A. \& Mackauer M. 1999: Host handling and specificity of the hyperparasitoid wasp, Dendrocerus carpenteri (Curtis) (Hym., Megaspilidae): importance of host age and species. $J$. Appl. Entomol. 123: 83-91.

Cloutier C. \& Bauduin F. 1990: Searching behavior of the aphid parasitoid Aphidius nigripes (Hymenoptera: Aphidiidae) foraging on potato plants. Environ. Entomol. 19: 222-228

Cloutier C., Lévesque A., Eaves D.M. \& Mackauer M. 1991: Maternal adjustment of sex ratio in response to host size in the aphid parasitoid Ephedrus californicus. Can. J. Zool. 69: 1489-1495.

Cloutier C., Duperron J., Tertuliano M. \& McNeil J.N. 2000: Host instar, body size and fitness in the koinobiotic parasitoid Aphidius nigripes. Entomol. Exp. Appl. 97: 29-40.

Colfer R.G. \& Rosenheim J.A. 2001: Predation on immature parasitoids and its impact on aphid suppression. Oecologia 126: $292-304$

COOK J.M. \& CROZIER R.H. 1995: Sex determination and population biology in the Hymenoptera. Trends Ecol. Evol. 10: 281-286.

Dettner K. \& Liepert C. 1994: Chemical mimicry and camouflage. Annu. Rev. Entomol. 39: 129-154.

Ferrari J., Darby A.C., Daniell T.J., Godfray H.C.J. \& Douglas A.E. 2004: Linking the bacterial community in pea aphids with host-plant use and natural enemy resistance. Ecol. Entomol. 29: 60-65.

Godfray H.C.J. 1994: Parasitoids: Behavioral and Evolutionary Ecology. Princeton University Press, Princeton, NJ, $473 \mathrm{pp}$

GRIFFITHS D.C. 1961: The development of Monoctonus paludum Marshall (Hym., Braconidae) in Nasonovia ribis-nigri on lettuce, and immunity reactions in other lettuce aphids. Bull. Entomol. Res. 52: 147-163.

HAN B. \& ChEN Z. 2002: Behavioral and electrophysiological responses of natural enemies to synomones from tea shoots and kairomones from tea aphids, Toxoptera aurantii. J. Chem. Ecol. 28: 2203-2219.

HARDY I.C.W. \& CooK J.M. 1995: Brood sex ratio variance, developmental mortality and virginity in a gregarious parasitoid wasp. Oecologia 103: 162-169.

Hardy I.C.W., DiJKstra L.J., Gillis J.E.M. \& Luft P.A. 1998: Patterns of sex ratio, virginity and developmental mortality in gregarious parasitoids. Biol. J. Linn. Soc. 64: 239-270.

Harvey J.A., Vet L.E.M., Jiang N. \& Gols R. 1998: Nutritional ecology of the interaction between larvae of the gregarious ectoparasitoid, Muscidifurax raptorellus (Hymenoptera: Pteromalidae), and their pupal host, Musca domestica (Diptera: Muscidae). Physiol. Entomol. 23: 113-120.

Harvey J.A., Bezemer T.M., Elzinga J.A. \& Strand M.R. 2004 Development of the solitary endoparasitoid Microplitis demolitor: host quality does not increase with host age and size. Ecol. Entomol. 29: 35-43.

HeInz K.M. 1996: Host size selection and sex allocation behaviour among parasitoid trophic levels. Ecol. Entomol. 21: 218-226.

Höller C., Borgemeister C., Haardt H. \& Powell W. 1993 The relationship between primary parasitoids and hyperparasitoids of cereal aphids: an analysis of field data. J. Anim. Ecol. 62: 12-21.

Höller C., Micha S.G., Schulz S., Francke W. \& Pickett J.A. 1994: Enemy-induced dispersal in a parasitic wasp. Experientia 50: $270-278$.
HÜBNER G. \& VöLKL W. 1996: Behavioral strategies of aphid hyperparasitoids to escape aggression by honeydewcollecting ants. J. Ins. Behav. 9: 143-157.

HUFBAUER R.A. 2002: Evidence for nonadaptive evolution in parasitoid virulence following a biological control introduction. Ecol. Applications 12: 66-78.

Hufbauer R.A. \& VIA S. 1999: Evolution of an aphid-parasitoid interaction: variation in resistance to parasitism among aphid populations specialized on different plants. Evolution 53: $1435-1445$.

Kaneko S. 2003: Impacts of two ants, Lasius niger and Pristomyrmex pungens (Hymenoptera: Formicidae), attending the brown citrus aphid, Toxoptera citricidus (Homoptera: Aphididae), on the parasitism of the aphid by the primary parasitoid, Lysiphlebus japonicus (Hymenoptera: Aphidiidae), and its larval survival. Appl. Entomol. Zool. 38: 347-357.

Kanuck M.J. \& Sullivan D.J. 1992: Ovipositional behavior and larval development of Aphidencyrtus aphidivorus (Hymenoptera: Encyrtidae), an aphid hyperparasitoid. J. N. Y. Entomol. Soc. 100: 527-532.

KING B.H. 1993: Sex ratio manipulation by parasitoid wasps. In Wrensch D.R. \& Ebbert M.A. (eds): Evolution and Diversity of Sex Ratio in Insects and Mites. Chapman \& Hall, New York, pp. 418-441.

KuINGAUF F. 1966: Abwehr- und Meidereaktionen von Blattläusen (Aphididae) bei Bedrohung durch Räuber und Parasiten. Z. Angew. Entomol. 60: 269-317.

LiePERT C. \& DetTNER K. 1993: Recognition of aphid parasitoids by honeydew-collecting ants: the role of cuticular lipids in a chemical mimicry system. J. Chem. Ecol. 19: 2143-2153.

Losey J.E. \& Denno R.F. 1998: The escape response of pea aphids to foliar-foraging predators: factors affecting dropping behaviour. Ecol. Entomol. 23: 53-61.

Luck R., Messenger P.S. \& Barbieri J.F. 1981: The influence of hyperparasitism on the performance of biological control agents. In Rosen D. (ed.): The Role of Hyperparasitism in Biological Control: a Symposium. Division of Agricultural Sciences, University of California, Berkeley, CA, Vol. 4103: 34-42.

MACKAUER M. 1976: The sex ratio in field populations of some aphid parasites. Ann. Entomol. Soc. Am. 69: 453-456.

Mackauer M. \& LARDNER R.M. 1995: Sex-ratio bias in an aphid parasitoid-hyperparasitoid association: a test of two hypotheses. Ecol. Entomol. 20: 118-124.

Mackauer M. \& StarÝ P. 1967: World Aphidiidae (Hym. Ichneumonoidea). Le François, Paris, 195 pp.

MACKAUER M. \& VÖLKL W. 1993: Regulation of aphid populations by aphidiid wasps: does parasitoid foraging behaviour or hyperparasitism limit impact? Oecologia 94: 339-350.

MACKAUER M. \& VÖLKL W. 2002: Brood-size and sex-ratio variation in field populations of three species of solitary aphid parasitoids (Hymenoptera: Braconidae, Aphidiinae). Oecologia 131: 296-305.

Mackauer M., Michaud J.P. \& VöLKL W. 1996: Host choice by aphidiid parasitoids (Hymenoptera: Aphidiidae): host recognition, host quality, and host value. Can. Entomol. 128: 959-980.

MeyнÖFER R. \& KLUg T. 2002: Intraguild predation on the aphid parasitoid Lysiphlebus fabarum (Marshall) (Hymenoptera: Aphidiidae): mortality risks and behavioral decisions made under the threats of predation. Biol. Control 25: 239-248.

Mishra S. \& Singh R. 1991: Sex ratio of the aphid parasitoid Lysiphlebus delhiensis (Subba Rao \& Sharma) (Hym., Aphidiidae) in field populations. J. Appl. Entomol. 111: 72-77. 
Nagelkerke C.J. \& Hardy I.C.W. 1994: The influence of developmental mortality on optimal sex allocation under local mate competition. Behav. Ecol. 5: 401-411.

Oliver K.M., Russell J.A., Moran N. \& Hunter M.S. 2003: Facultative bacterial symbionts in aphids confer resistance to parasitic wasps. Proc. Nat. Acad. Sci. USA 100: 1803-1807.

Otто M. \& Mackauer M. 1998: The developmental strategy of an idiobiont ectoparasitoid, Dendrocerus carpenteri: influence of variations in host quality on offspring growth and fitness. Oecologia 117: 353-364.

Pandey S. \& Singh R. 1999: Host size induced variation in progeny sex ratio of an aphid parasitoid Lysiphlebia mirzai. Entomol. Exp. Appl. 90: 61-67.

Salt G. \& van DEN Bosch R. 1967: The defense reactions of three species of Hypera (Coleoptera, Curculionidae) to an ichneumon wasp. J. Invertebr. Path. 9: 164-177.

SANDLAN K. 1979: Sex ratio regulation in Coccygomimus turionella Linnaeus (Hymenoptera: Ichneumonidae) and its ecological implications. Ecol. Entomol. 4: 365-378.

Sequeira R. \& Mackauer M. 1992: Nutritional ecology of an insect host-parasitoid association: the pea aphid - Aphidius ervi system. Ecology 73: 183-189.

SEQUeIRA R. \& MACKAUER M. 1993: Seasonal variation in body size and offspring sex ratio in field populations of the parasitoid wasp, Aphidius ervi (Hymenoptera: Aphidiidae). Oikos 68: $340-346$.

Singh R. \& PANDEY S. 1997: Offspring sex ratio in Aphidiinae (Hymenoptera: Braconidae): a review and bibliography. $J$. Aphidol. 11: 61-82.

SNYDER W.E. \& IVES A.R. 2003: Interactions between specialist and generalist natural enemies: parasitoids, predators, and pea aphid biocontrol. Ecology 84: 91-107.

SoKal R.R. \& RohlF F.J. 1995: Biometry, 3rd ed. W.H. Freeman, New York, NY, 887 pp.

StADLER B. \& Mackauer M. 1996: Influence of plant quality on interactions between the aphid parasitoid Ephedrus californicus Baker (Hymenoptera: Aphidiidae) and its host, Acyrthosiphon pisum (Harris) (Homoptera: Aphididae). Can. Entomol. 128: 27-39.

Sullivan D.J. \& VölKL W. 1999: Hyperparasitism: multitrophic ecology and behaviour. Annu. Rev. Entomol. 44: 291-315.

Suzuki Y., Tsuji H. \& Sasakawa M. 1984: Sex allocation and effects of superparasitism on secondary sex ratios in the gregarious parasitoid, Trichogramma chilonis (Hymenoptera: Trichogrammatidae). Anim. Behav. 32: 478-484.
TAKAGI M. 1986: The reproductive strategy of the gregarious parasitoid, Pteromalus puparum (Hymenoptera: Pteromalidae). 2. Host size discrimination and regulation of the number and sex ratio of progeny in a single host. Oecologia 70: $321-325$.

VISSER M.E. 1994: The importance of being large: the relationship between size and fitness in females of the parasitoid Aphaereta minuta (Hymenoptera: Braconidae). J. Anim. Ecol. 63: 963-978.

VöLKL W. 1994: The effect of ant-attendance on the foraging behaviour of the aphid parasitoid Lysiphlebus cardui. Oikos 70: 149-155.

VöLKL W. 1997: Interactions between ants and aphid parasitoids: patterns and consequences. In Dettner K., Bauer G. \& Völkl W. (eds): Vertical Food Web Interactions: Evolutionary Patterns and Driving Forces. Springer, Berlin, pp. 225-240 (Ecological Studies 130).

VÖLKL W. \& MACKAUER M. 2000: Oviposition behaviour of aphidiine wasps (Hymenoptera: Braconidae, Aphidiinae): morphological adaptations and evolutionary trends. Can. Entomol. 132: 197-212.

VÖLKL W., HÜBNER G. \& DetTNER K. 1994: Interactions between Alloxysta brevis (Hymenoptera, Cynipoidea, Alloxystidae) and honeydew collecting ants: how an aphid parasitoid overcomes ant aggression by chemical defense. J. Chem. Ecol. 20: 2621-2635.

VölkL W., Kranz P., Weisser W. \& HüBner G. 1995: Patch time allocation and resource exploitation in aphid primary parasitoids and hyperparasitoids searching simultaneously within aphid colonies. J. Appl. Entomol. 119: 399-404.

WAAGE J.K. 1986: Family planning in parasitoids: adaptive patterns of progeny and sex allocation. In Waage J. \& Greathead D. (eds): Insect Parasitoids. 13th Symposium of the Royal Entomological Society of London. Academic, London, pp. 63-95.

WEISSER W.W. 2000: Metapopulation dynamics in an aphidparasitoid system. Entomol. Exp. Appl. 97: 83-92.

Wellings P.W., Morton R. \& Hart P.J. 1986: Primary sex-ratio and differential progeny survivorship in solitary haplo-diploid parasitoids. Ecol. Entomol. 11: 341-348.

WyLIE H.G. 1965: Effects of superparasitism on Nasonia vitripennis (Walk.) (Hymenoptera: Pteromalidae). Can. Entomol. 97: 326-331.

Received December 8, 2004; revised February 15, 2005; accepted February 15, 2005 